\title{
Development of an Optimization Model to Manage Imbalances in Power Systems by Local Power Retail Companies
}

\author{
Ryuji Matsuhashi \\ Professor, Department of Electrical Engineering and Information Systems, Graduate School of the University of Tokyo, 113-8656 Tokyo, \\ Japan
}

\begin{abstract}
The feed-in tariff (FIT) programs resulted in rapid growth of renewable power sources in various countries. In Japan, the program particularly triggered explosive growth of solar power generations because of its short leadtime and high tariff level. Although mass introduction of renewable power sources certainly contributes to reduce $\mathrm{CO} 2$ emissions, it causes serious instability issues in power systems. One of the most serious issues is management of imbalances resulting from forecast errors in solar power generations. These imbalances must be compensated so as to keep stable operation in power systems. On the other hand, local power retail companies are increasing nowadays in various countries including Japan. These companies are mainly procuring renewable power sources such as solar power systems.Taking these circumstances into consideration, this article aims at exploring measures to manage the imbalances of power systems by local power retail companies. For this purpose, we developed a model in mixed integer linear programming to operate power systems dealing with the imbalances. Evaluated results using the model indicated the followings; appropriate adoption of stationary or home batteries is shown to economically compensate the imbalances by local power retail companies.
\end{abstract}

\section{Introduction}

Paris agreement, which was adopted in 2015, is a significant international framework to reduce greenhouse gas emissions from 2020. Taking Paris agreement into consideration, Japanese government determined a plan to reduce greenhouse gas emissions by $26.0 \%$ in 2030 compared with 2013. [1]

Ministry of Economy, Trade and Industry in Japan issued the long-term outlook for energy supply and demand in 2015, which is consistent with the above plan. [2] In particular, the share of renewable power sources in total power mixes increased up to $22 \%$ or to $24 \%$, in which the share of solar power generation is around $7 \%$. Thus the solar power generation is placed as a second renewable power source following the hydraulic power generation.

In Japan, the feed-in tariff (FIT) program, that began in 2013, triggered explosive growth of renewable power sources, particularly solar power generations because of its short lead-time and high tariff level.

However, mass introduction of renewable power sources is causing serious instability issues; outputs of solar power generation are uncertain, causing power system instability. In unit commitments to schedule starts and stops of each power plant in advance, operators have to forecast solar and wind power outputs in future. But this forecast inevitably includes errors due to uncertainty in future weather conditions. [3] As results, operators manage the imbalances resulting from the above forecast errors. So as to keep stable operation of power systems in case of the larger imbalances than ever, operators must prepare more adjusting power to compensate the imbalances, leading to higher operation costs. Thus management of the imbalances is one of the most serious issues.

On the other hand, local power retail companies are increasing nowadays in various countries including Japan. These companies are mainly procuring renewable power sources such as solar power generation systems.

Taking these circumstances into consideration, it is significant for the local power retail companies to reduce the imbalances by themselves. If they can appropriately manage and compensate the imbalances, that also contributes to the stable management of entire power systems. Regarding analyses in this field, Takahashi [4] developed a mathematical model to operate power systems in the uncertainty. But it is not for local power retail companies, but for large electric utilities.

In this article, we aim at developing technological systems to manage and compensate the imbalances for the local power retail companies.

\section{Methodologies adopted in this article}

This sector deals with an objective functions, constraints and data assumptions in the mathematical model for 
simulating power systems of the evaluated local power retail companies.

\subsection{Objective function}

In this study, the power system is determined, so that the total profit taking revenues and costs takes a maximum value. The power system is represented with a mixed integer linear programming model. The revenues come from electricity retail for high-voltage and low-voltage customers. The costs consist of procurement of electricity from the contracted solar power generators, wholesale electricity traded in JEPX, Japan Electric Power Exchange, ordinary back up electricity from Kyushu Electric Utility, the costs of batteries and the wheeling payment. The wheeling costs paid to the Kyushu Electric Utility are also included, since the local power retail company uses the power transmission and the distribution lines owned by the utility.

$$
\begin{aligned}
& \text { Maximum } P_{\text {tot }}=R_{\text {tot }}-C_{\text {tot }} \\
& C_{\text {tot }}=C_{P V}+C_{B U}+C_{W R}+C_{M}+C_{I B} \\
& R_{L}=R_{L, \text { base }}+\sum_{t}\left(L_{L}(t) \times R P_{L}(t)\right) \\
& R_{H}=R_{H, \text { base }}+\sum_{t}\left(L_{H}(t) \times R P_{H}(t)\right) \\
& C_{P V}=\sum_{t}\left(G_{P V}(t) \times P P_{P V}(t)\right) \\
& C_{B U}=C_{B U, \text { base }}+\sum_{t}\left(G_{B U}(t) \times P P_{B U}(t)\right) \\
& C_{W R}=C_{W R, \text { base }}+\sum_{t}\left(W R_{H}(t) \times P T_{H}(t)+W R_{L}(t) \times P T_{L}(t)\right) \\
& C_{M}=\sum_{t}\left(G_{M}(t) \times P P_{M}(t)\right) \\
& C_{I B}=\sum_{t}\left(I B_{E X P}(t) \times P E_{I B}(t)\right)
\end{aligned}
$$

$\mathrm{P}_{\text {tot }}$; Cash flow of the local power retail company, $\mathrm{R}_{\text {tot }}$; Cash inflow of the local power retail company, $\mathrm{C}_{\text {tot }}$; Cash outflow of the local power retail company, $R_{L}$; Cash inflow from low-voltage consumers, $R_{H}$; Cash inflow from high-voltage consumers, $C_{P V}$; Procurement cost of electricity from PV, $C_{B U}$; Procurement cost of electricity based on the ordinary buck up contract, $C_{W R}$; Wheeling cost, $C_{M}$; Procurement cost of electricity from Japan Electric Power Exchange, $C_{I B}$; Expected cost of penalty for imbalance, $R_{L, \text { base }}$; Basic charge by low voltage retail contracts, $R_{H, \text { base }}$; Basic charge by high voltage retail contracts, $R P_{L}(t)$; Amount-based charge by low voltage retail contracts, $R P_{H}(t)$; Amount-based charge by high voltage retail contracts, $P P_{P V}(t)$; Procurement rate of electricity from $\mathrm{PV}, C_{B U, \text { base }}$; Basic rate of ordinary back up contract, $P P_{B U}(t)$; Procurement rate of electricity based on the ordinary buck up contract, $C_{W R \text {, base }}$; Basic charge of wheeling, $P T_{H}(t)$; Amount-based rate of high voltage wheeling, $P T_{L}(t)$; Amount-based rate of low voltage wheeling, $P P_{M}(t)$; Wholesale rate of electricity in Japan Electric Power Exchange, $P E_{I B}(t)$; Penalty rate for imbalances, $L_{L}(t)$, Planned value of low voltage demand, $L_{H}(t)$; Planned value of high voltage demand, $G_{P V}(t)$, Planned value of procuring PV outputs, $G_{B U}(t)$; Planned value of procuring ordinary back up electricity, $W R_{H}(t)$; Planned value of wheeling at high voltage, $W R_{L}(t)$; Planned value of wheeling at low voltage, $G_{M}(t)$; Planned value of procuring electricity from JEPX, $I B_{E X P}(t)$; Expected value of Imbalance,

\subsection{Constraints on balances between supply and demand}

The sum of electricity demand must be equal to the sum of electricity supply in each time slot.

\subsection{Constraints on states of charge in batteries}

The SOC, state of charge in batteries in each time slot must be higher than a designated minimum value, and lower than a designated maximum value.

In each time slot, a present SOC is estimated taking account of the SOC, charge and discharge before one step.

The maximum power for charging and discharging batteries must also be lower than designated values.

The ratio of the battery's capacity to the power conditioner in the stationary one is assumed to be 2.0 , while it is 5.5 in the home battery. We adopted these ratios on the basis of actual batteries sold in the market [5].

\subsection{Imbalances resulting from forecast errors in solar power generations}

Forecast in solar power outputs inevitably includes errors. Takahashi [3] evaluated RMSE, root mean square error, in the forecast. According to this, the probability density function of the forecast errors is near to a Laplacian distribution, and the value of RMSE is approximately $10 \%$ in the one-day-ahead forecast.

Therefore we adopted the Laplacian distribution with $10 \%$ of RMSE in developing a model of probabilistic imbalances resulting from the above forecast errors. The figure 1 depicts the forecast errors.

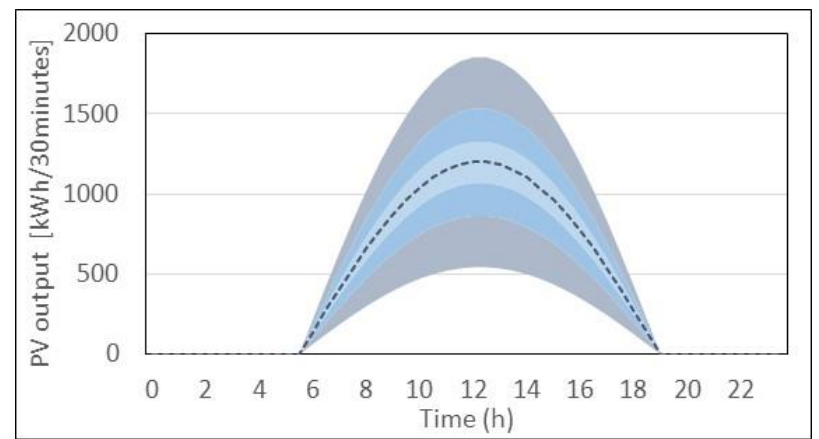


Figure 1. Errors in forecasting solar power outputs.

\subsection{Assumptions on electricity demand}

Regarding electricity demand, we assumed the high and low voltage demand as shown in figures 2 and 3 . We set these demands on the basis of an actual local power retail company. [6]

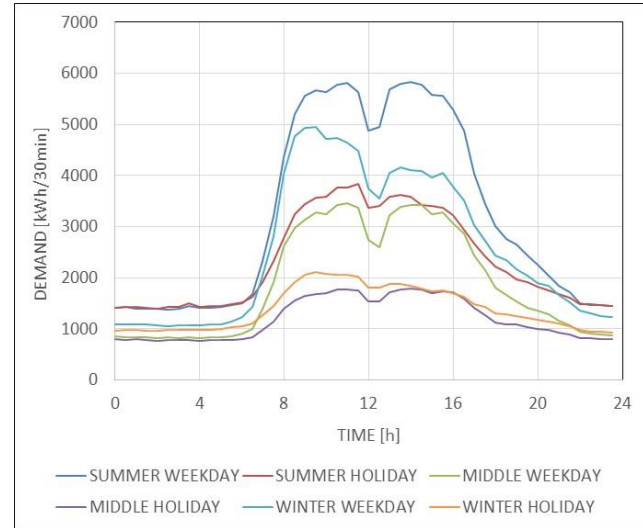

Figure 2. High voltage electricity demand.

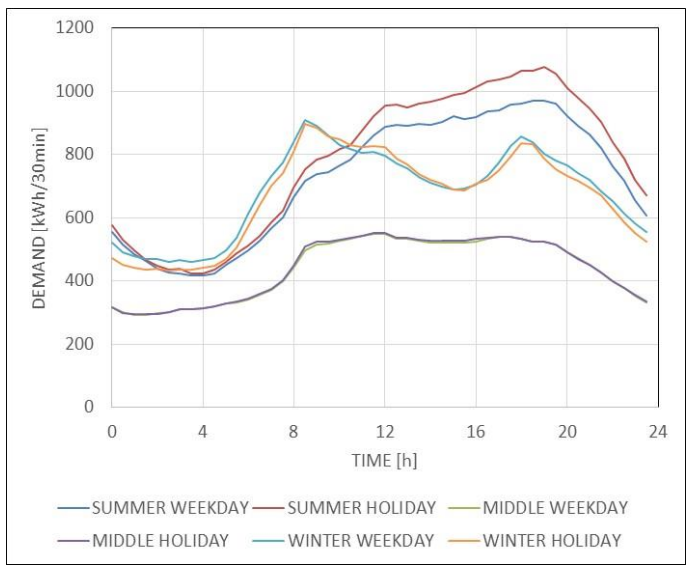

Figure 3. Low voltage electricity demand.

\subsection{Assumptions on prices of electricity procured and sold by the local power retail company}

Figure 4 shows wholesale prices, by which the local power retail company procure electricity. The database is developed based on the price traded in JEPX. [7]

On the other hand, the local power company sell electricity in the retail prices as shown in figure 5. [6]

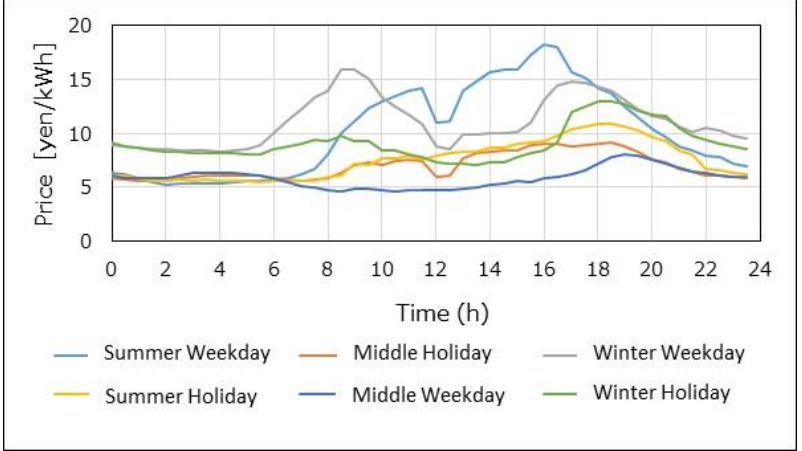

Figure 4. The assumed price procured from the power wholesale market.

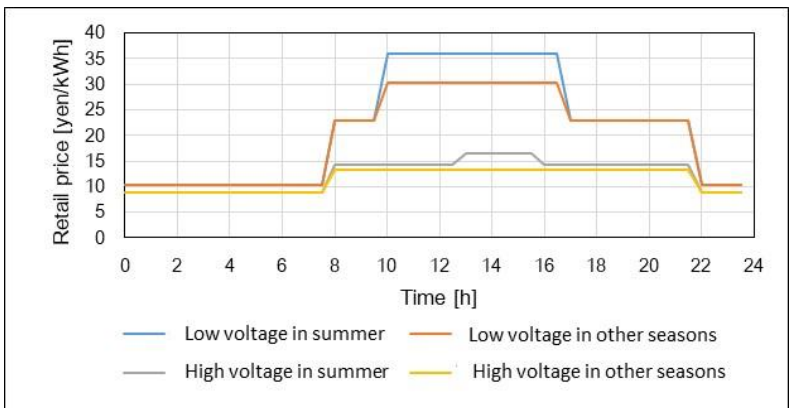

Figure 5. The assumed retail price of electricity sold in the local power retail company.

\section{Evaluated results and discussions}

Using the optimization model described in the last chapter, we compared the performances of stationary batteries with home batteries. In the figures below, sensitivity analyses were applied for the penalty costs. For instance, "Penalty for imbalance $\times n$ " means that the price for imbalance penalty is $n$ times higher than the back-up electricity from the electric utilities.

We first evaluated the relationships between capacities of the batteries and rate of residual imbalances. Figures 6 and 7 depict the cases of stationary and home batteries, respectively. These figures show that imbalances are gradually reduced by increasing the batteries in both cases, although we note that the imbalance in the case of "Penalty for imbalance $\times 1$ " was not decreased as other cases in stationary batteries. The reason is as follows. In the case of using the stationary batteries, it takes wheeling costs to compensate the imbalances. If the wheeling costs is higher than the penalty of imbalances, it is optimal not to compensate the imbalances. Therefore some of the imbalances are not to be compensated in the case of low penalty costs as shown in figure 6.

On the other hand, it does not take wheeling costs to compensate the imbalances within each house by the home batteries. Thus the imbalances decrease irrelevant of penalty costs for the home batteries as shown in figure 7. 


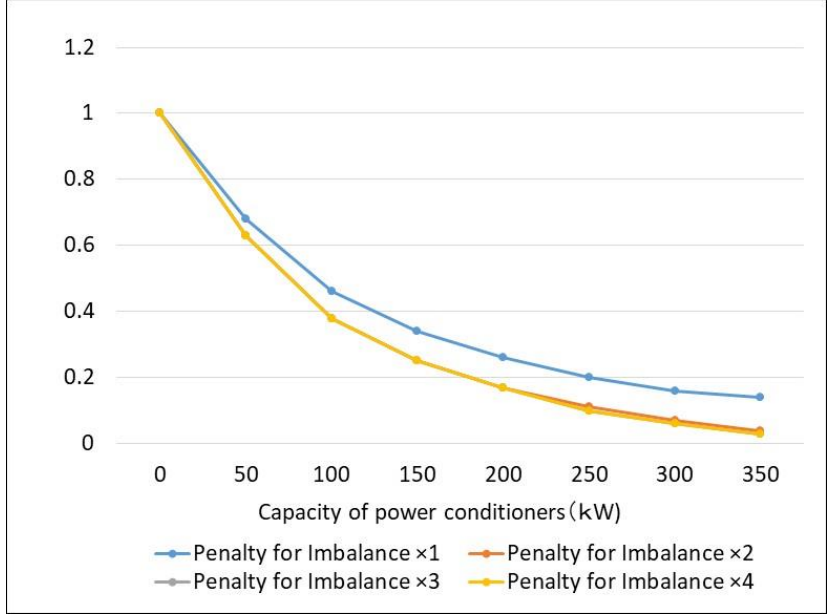

Figure 6. Relationships between rate of residual imbalances and capacities of the stationary batteries.

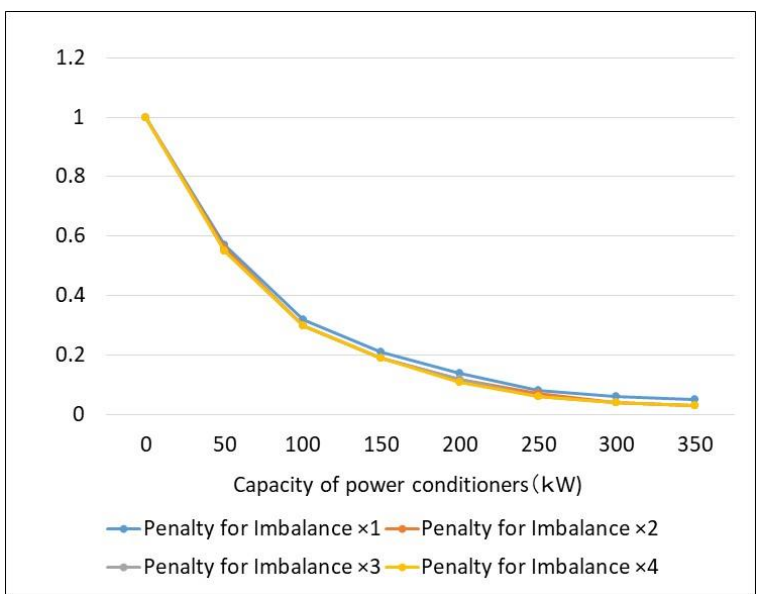

Figure 7. Relationships between rate of residual imbalances and capacities of the home batteries.

Figure 8 depicts relationships between capacities of the stationary batteries and total profits of the local power retail company. In the cases of "Penalty for imbalance $\times 1$ ", the graph shows monotonous decrease with increasing capacities of the batteries. Highest profits are without batteries in the case.

On the other hand, the graphs are not monotonous decrease in the cases of "Penalty for imbalance $\times 2$ ", "Penalty for imbalance $\times 3$ " and "Penalty for imbalance $\times 4$ ". Highest profits are with a certain amount of batteries in these cases. These are because penalty costs are higher than the costs of the stationary batteries. Thus lowering of the costs of batteries is significant for compensating imbalances with them.

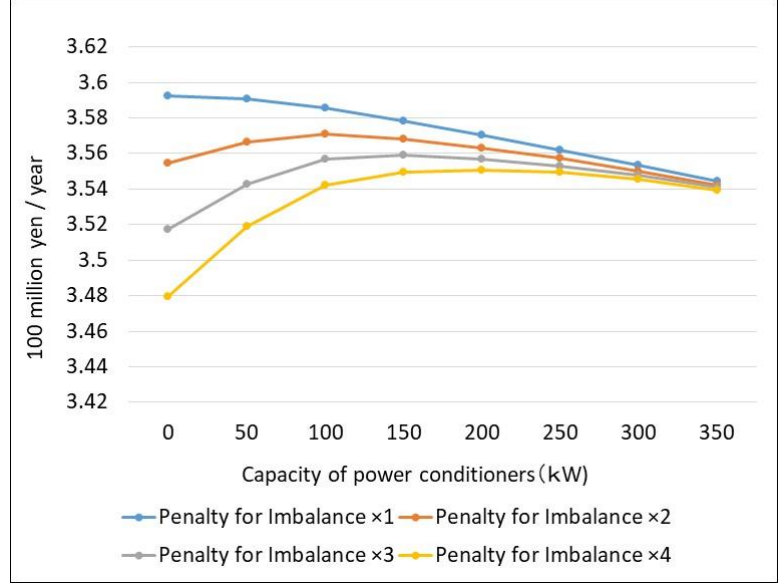

Figure 8. Relationships between annual cash flows of regional power retail companies and capacities of the stationary batteries.

Figure 9 depicts relationships between capacities of the home batteries and total profits of the local power retail company. In the cases of "Penalty for imbalance $\times 1$ " and "Penalty for imbalance $\times 2$ ", the graphs show monotonous decrease with increasing capacities of the batteries. Highest profits are without batteries in the case. On the other hand, the graphs are not monotonous decrease in the cases of "Penalty for imbalance $\times 3$ " and "Penalty for imbalance $\times 4$ ". Highest profits are with a certain amount of batteries in these cases.

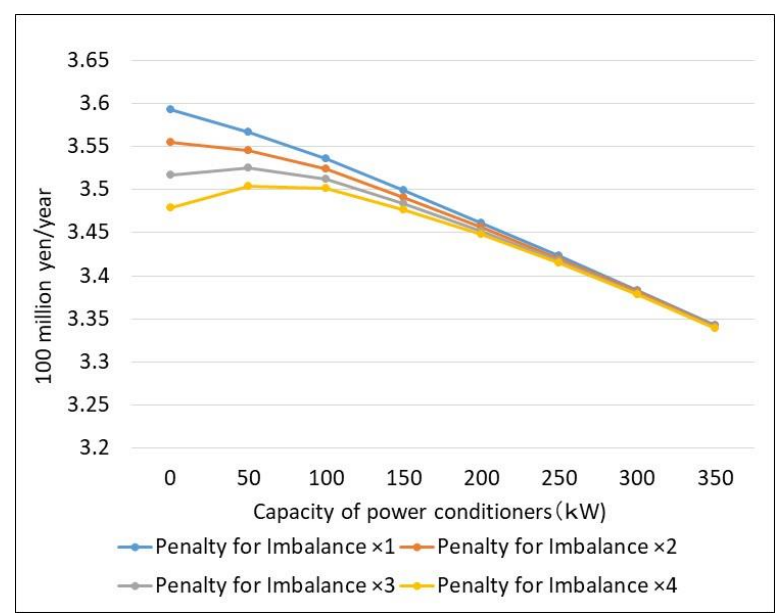

Figure 9. Relationships between annual cash flows of regional power retail companies and capacities of the home batteries.

Figures 10 and 11 depict relationships between changing costs and capacities of the stationary and home batteries, respectively. In figure 10 , we need to take balances between decreasing penalty, increasing wheeling costs at low voltage, and increasing battery costs into consideration to find the highest cash flow point. 


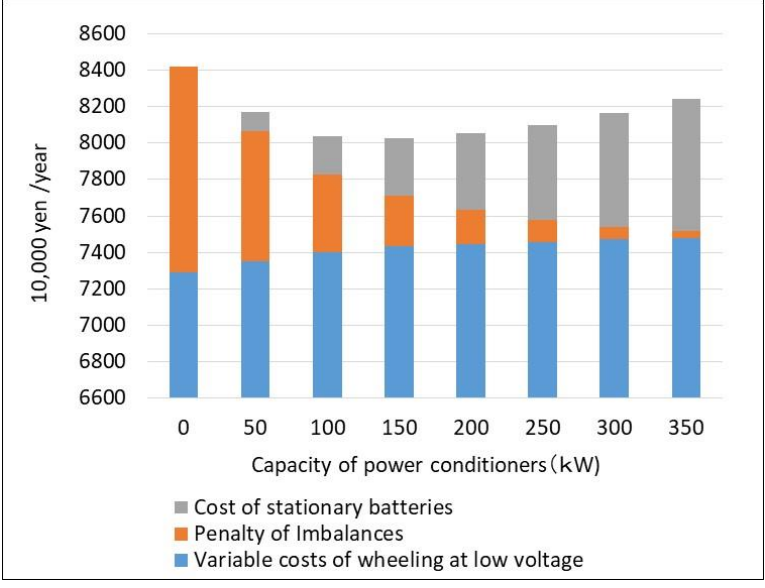

Figure 10. Relationships between changing costs and capacities of the stationary batteries, when the imbalance penalty is 3 times higher than that of ordinary back-up power.

Figure 11 shows that balances between decreasing penalty and increasing battery costs determine the highest cash flow point.

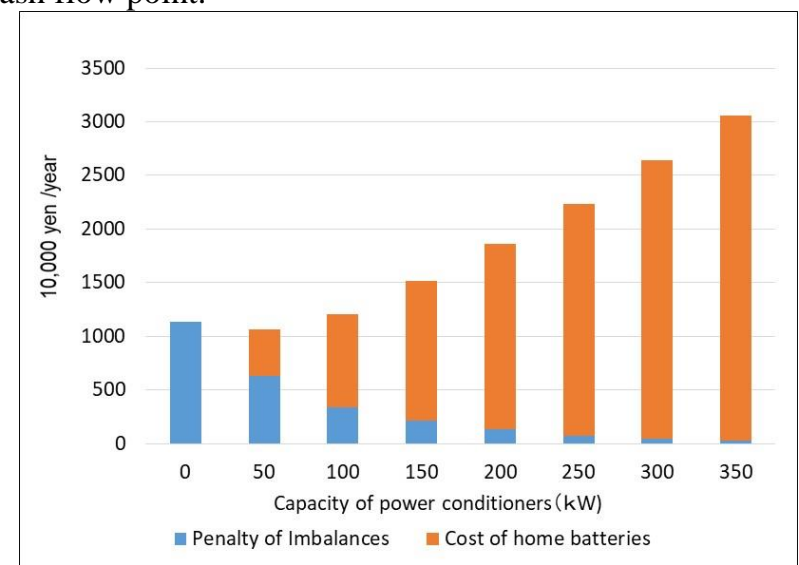

Figure 11. Relationships between changing costs and capacities of the home batteries, in the case that the penalty cost of imbalances is 3 times higher than that of ordinary back up power.

\section{Conclusion}

It is significant to maintain stable management of power systems, regardless of mass introduction of solar power systems. In this article, we intend to compensate imbalances of power systems resulting from errors in forecasting solar power outputs. For this purpose, we developed a model in mixed integer linear programming to operate power systems dealing with the imbalances.
Evaluated results using the above mathematical model indicated the followings. The profits of the local power companies could be improved by the appropriate combination of solar power generation and batteries as well as imbalances could considerably be reduced, if the cost of batteries is lower than certain values.

Comparative analysis of stationary and home batteries revealed the followings. Stationary batteries have advantages regarding economy of scale. On the other hand, home batteries have advantages in that wheeling costs are saved because of in-house use of home batteries. Thus we also quantitatively estimated trade-off relationships between stationary and home batteries.

\section{References}

1. Global Warming Prevention Headquarters, Draft of Commitment of Japan, July 17th, 2015 [Online]. Available:

http://www.kantei.go.jp/jp/singi/ondanka/kaisai/dai3 0/yakusoku_souan.pdf [Access date: 11th, April, 2018].

2. Ministry of Economy, Trade and Industry, Longterm outlook for energy supply and demand, July 16th, 2015 [Online].

Available: http://www.meti.go.jp/press/2015/07/20150716004/2 0150716004_2.pdf [Access date: 11th, April, 2018].

3. M. Takahashi and R. Matsuhashi, "Area-wide Total Wind and Photovoltaic Power Forecasting Using Multiple Regression Technique and Analysis of Forecast Error Characteristics", Journal of Japan Society of Energy and Resources, 38, 5, 2017.

4. M. Takahashi and R. Matsuhashi, "A Cost Reduction Analysis of Introduction of Battery Energy Storage and Controllable Heat Pump Water Heaters by Operation Planning Model of Power Generation System Considering the Uncertainty in Renewable Power Generation", Transactions on Power and Energy (Journal Sector B), Japan Institute of Electrical Engineering, 137, 12, 2017.

5. Tesla, Powerpack / Commercial and Utility Energy Storage Solutions, [Online]. Available: https://www.tesla.com/powerpack. [Access date: 11th, April, 2018].

6. Miyama Smart Energy. [Online]. Available: http://miyama-se.com/electrical/simmenu/sim-ans-index. [Access date: 2017.11.16]

7. JEPX, JEPX trading information, [Online]. Available: http://www.jepx.org/market/index.html. [Access date: 2017.11.17]. 